\title{
A Escola Austríaca e o Mercado das Ideias Fabio Barbieri*
}

$\mathrm{O}$ $s$ editoriais de Ubiratan Jorge Iorio $^{1}$ e de Alex Catharino ${ }^{2}$ no primeiro volume da MISES: Revista Interdisciplinar de Filosofia, Direito e Economia ofereceram uma caracterização tanto das teorias quanto da metodologia que distinguem a Escola Austríaca. Tomando como base essa caracte-

1 IORIO, Ubiratan Jorge. A Escola Austríaca na Vanguarda. MISES: Revista Interdisciplinar de Filosofia, Direito e Economia, Vol. I, No. 1, jan.-jun. 2013: 3-18.

2 CATHARINO, Alex. A Escola Austríaca entre a Tradição e a Inovação. MISES: Revista Interdisciplinar de Filosofia, Direito e Economia, Vol. I, No. 2, jul.-dez. 2013: 305-23. rização, iniciamos este primeiro número do segundo volume do periódico continuando a reflexão sobre o futuro dessa tradição de pesquisa. Abordaremos três aspectos em particular, todos eles associados à relação entre os economistas austríacos e as demais teorias econômicas. Em primeiro lugar, discutiremos a importância do pensamento austríaco para a Economia, em particular, e para as Ciências Sociais, em geral. Na sequência, defenderemos a opinião de que o desenvolvimento das teorias da Escola Austríaca depende da adoção de uma postura intelectual aberta e humilde no mercado das ideias, em contraste com o sectarismo e dogmatismo que com frequência acompanham a consolidação de

\footnotetext{
“ Fabio Barbieri nasceu em 14 de maio de 1970, em São Paulo, SP. É professor da Faculdade de Economia, Administração e Contabilidade de Ribeirão Preto da Universidade de São Paulo (FEA-RP/USP), além de Editor Adjunto e membro do Conselho Editorial de MISES: Revista Interdisciplinar de Filosofia, Direito e Economia. Cursou o bacharelado em Administração Pública na Fundação Getúlio Vargas de São Paulo (FGV-SP) e o mestrado e o doutorado em Economia pela USP. Foi professor da Universidade Presbiteriana Mackenzie e do Centro Universitário FECAP. É autor de diversos artigos acadêmicos publicados em diferentes periódicos e dos livros História do Debate do Cálculo Econômico Socialista (Instituto Ludwig von Mises Brasil, 2013) e A Economia do Intervencionismo (Instituto Ludwig von Mises Brasil, 2013), bem como, coautor das obras Manual de Microeconomia (Editora Atlas, 2011) e Metodologia do Pensamento Econômico: O Modo de Fazer Ciência dos Economistas (Editora Atlas, 2013).

E-mail: barbieri@mises.org.br
} 
uma tradição teórica. Por fim, no que diz respeito à substância das teorias austríacas, argumentaremos que um efetivo progresso nesse campo requer o enfrentamento de uma tensão, presente desde Carl Menger (18401921), entre duas características centrais da escola: o subjetivismo e a complexidade do problema econômico.

Esse conjunto de tópicos gravita em torno da consolidação e aumento da influência da Escola Austríaca. É bem conhecida a história dessa consolidação ${ }^{3}$ : da revolução marginalista na década de 1870 até a década de 1930, as contribuições austríacas foram vistas como parte da emergente tradição neoclássica; a partir do debate sobre o cálculo econômico socialista e do advento da revolução keynesiana, surge a consciência de que os austríacos trabalham com tradição de pesquisa própria, com seu conjunto peculiar de problemas de investigação e ferramentas analíticas e, depois desse fértil período marcado pelos trabalhos de Ludwig von Mises (1881-1973) e F. A. Hayek (18991992), que quase em isolamento corajosamente defenderam suas convicções, a Escola Austríaca ressurge na década de setenta como uma comunidade de pesquisadores dedicada ao desenvolvimento dessa tradição.

A essa história poderíamos acrescentar uma quarta fase, contemporânea. Esta é caracterizada tanto pelo aumento da demanda pelas explicações austríacas, impulsionada pelo crescente ceticismo em relação às teorias do mainstream, em especial no campo da macroeconomia, quanto pelo aumento da oferta dessas mesmas explicações austríacas, com o auxílio da internet, que possibilitou furar o bloqueio ao virtual monopólio intelectual que impera nas universidades. Em breve, apesar da educação baseada em livros-textos, não será mais possível que a maioria absoluta dos

\footnotetext{
${ }^{3}$ Ver, por exemplo, DOLAN, Edwin G. (Ed.). Foundations of Modern Austrian Economics. Kansas: Sheed Andrews and McMeel, 1976; VAUGHN, Karen I. Austrian Economics in America: The Migration of a Tradition. Cambridge: Cambridge University Press, 1998.
}

estudantes de economia se forme sem sequer ouvir falar de Mises ou Hayek.

Pois bem, dada essa fase presente de expansão e maior visibilidade, o pesquisador austríaco deve estar atento aos desafios impostos pelo momento. Qual postura adotar? Que caminho tomar?

Nossa tentativa de respostas a essas questões procura livrar-se das amarras impostas pela filosofia da ciência moderna, que irresistivelmente nos leva a buscar as características centrais de paradigmas ou programas de pesquisa científicos. Cremos que essa sociologia do conhecimento de Thomas Kuhn (1922-1996) deva ser substituída pela mais fértil economia do conhecimento de Karl Popper (1902-1994), que indaga quais são as instituições e posturas intelectuais compatíveis com o progresso científico impulsionado pela rivalidade (competição) entre ideias. Afinal, os austríacos, como economistas liberais, estão na feliz situação de oferecer uma justificativa uniforme, falibilista, para a liberdade, tanto nos mercados quanto no mundo das ideias, ao contrário dos acadêmicos intervencionistas defensores da liberdade acadêmica, que colocam para si a curiosa tarefa de explicar porque o mercado das ideias seria o único a não apresentar falhas que justifiquem intervenções ${ }^{4}$.

Sendo assim, a mensagem principal deste texto consiste na seguinte recomendação: os acadêmicos austríacos modernos deveriam seguir a tradição dos grandes economistas austríacos do passado, dedicando parte considerável de seus esforços ao exame aprofundado de teorias rivais. Exploremos alguns aspectos dessa recomendação.

\section{I}

Vejamos inicialmente o que a comunidade acadêmica como um todo tem a ganhar com o diálogo crítico com os austríacos, para

\footnotetext{
${ }^{4}$ COASE, Ronald. The Market for Goods and the Market for Ideas. The American Economic Review, Vol. 64, No. 2, (May, 1974): 384-91.
} 
na seção seguinte explorar o que estes últimos lucrariam com tal diálogo.

O diálogo com os austríacos é fundamental para o enriquecimento do debate econômico e para a discussão mais ampla das ciências sociais, entre outros motivos, pela vantagem conferida por sua postura metodológica. Com o domínio da crença empiricista na economia e a sua difusão nas demais ciências sociais, cada vez mais o apriorismo austríaco se faz necessário.

Essa afirmação, que neste momento irresistivelmente provoca um sorriso condescendente no rosto de nosso eventual leitor "ortodoxo", pode ser constatada empiricamente. A despeito de um dos santos patronos do empirismo em Economia, Paul Samuelson (1915-2009), declarar seu temor pelo futuro da disciplina diante das opiniões metodológicas de Ludwig von Mises e Frank H. Knight (1885$1972)^{5}$, existe uma longa tradição de opiniões austríacas descartadas como pseudocientíficas e ideológicas que, em retrospecto, se mostraram acertadas em comparação com as previsões derivadas de suas rivais, pretensamente mais científicas. De fato, a história intelectual nos mostra que estamos diante de um verdadeiro caso de erro sistemático (algo que não deveria existir na atual concepção de racionalidade dos economistas!) no que diz respeito aos julgamentos ortodoxos das análises austríacas.

Antes de ilustrar esse ponto com alguns exemplos, recapitulemos brevemente a causa desse fenômeno. Como mostraram Mises $^{6}$ e $\mathrm{Knight}^{7}$, as explicações dos fenômenos sociais

5 SAMUELSON, Paul. The Collected Scientific Papers of Paul A. Samuelson. Ed. Robert C. Merton. Cambridge: The MIT Press, 1972. Vol. 3. Citado em: BLAUG, Mark. Metodologia da Economia: $\mathrm{Ou}$, como os economistas explicam. Trad. Afonso Luís Medeiros dos Santos Lima. São Paulo: Edusp, 1993. p. 130.

6 Ver, por exemplo: MISES, Ludwig von. The Ultimate Foundation of Economic Science: An essay on method. New York: Foundation for Economic Education, 1978 [1962].

${ }^{7}$ Ver, por exemplo: KNIGHT, Frank H. "What is Truth" in Economics? Journal of Political Economy, Vol. 48, No. 1 (February 1940): 1-32. tomam como ponto de partida a ação humana proposital. Sendo assim, as categorias não observáveis de meios e fins são centrais. Como mostram John Stuart Mill (1806-1873) ${ }^{8}$ e F. A. Hayek $^{9}$, os fenômenos sociais são complexos, envolvendo a descrição de estruturas sujeitas à influência de inúmeras causas que interagem entre si e cujos valores se alteram continuamente. Sendo assim, descrições teóricas de estruturas (não capturáveis por variáveis agregadas) cujos detalhes não são observáveis são centrais.

Esses fatos relativos ao subjetivismo e complexidade do objeto estudado sugerem a existência, nas ciências sociais e em menor grau nas teorias sobre fenômenos complexos em geral, de um trade-off metodológico entre relevância e operacionalidade. Tornar uma explicação teórica empiricamente operacional implica na tendência de desconsiderar elementos subjetivos e estruturas que caracterizam a complexidade dos objetos investigados. Ocorre que, diante desse dilema, o economista defensor da unidade do método opta preferencialmente pela operacionalidade: a escolha alternativa tornaria sua investigação menos digna do qualificativo "científica", segundo sua concepção de ciência.

Tal opção metodológica, porém, é preferencial, mas não sistemática. Dada a complexidade do objeto investigado, qualquer hipótese muito específica (operacional) seria refutada no nascedouro, de modo que o economista na verdade é levado a escolher entre estar precisamente errado ou genérica e possivelmente correto. A saída usual desse dilema é o instrumentalismo metodológico, tal como apresentado por Milton Friedman

\footnotetext{
${ }^{8}$ MILL, John Stuart. On the Definition of Political Economy; and on the Method of Investigation Proper to It. In: MILL. John Stuart. Essays on Some Unsettled Questions of Political Economy. Kitchener: Batoche Books, 2000 [1844]; MILL. John Stuart. A System of Logic. New York: Harper \& Brothers, 1882. (Ebook: Gutteberg Project, 2009).

${ }^{9}$ HAYEK, F. A. The Theory of Complex Phenomena. In: HAYEK, F. A. Studies in Philosophy, Politics and Economics. London: Routledge, 1967. p. 22-42.
} 
(1912-2006) ${ }^{10}$, que torna aceitável o trabalho com hipóteses específicas e explicitamente falsas, desde que gerem previsões satisfatórias. Mas, se estruturas e subjetivismo realmente importam, tais previsões não serão especialmente boas, $\mathrm{o}$ que força o economista a abandonar na prática seu programa metodológico.

Isso explica as inconsistências do positivismo em economia. $\mathrm{O}$ exame da retórica dos economistas realizado por Donald $\mathrm{N}$. McCloskey ${ }^{11}$ ilustra perfeitamente nosso ponto: o positivismo em economia (denominado "modernismo" pelo autor) gera regras metodológicas não praticadas por seus defensores. Isso não poderia ser diferente, dada a incompatibilidade entre tal programa metodológico e a natureza do objeto investigado exposto no parágrafo anterior. Sendo assim, o exame empírico do desempenho de longo prazo da metodologia empiricista ironicamente nos revela o fracasso em seu próprio teste, tal como previsto a priori pelos críticos do positivismo.

Tomemos, como ilustração, um manual bastante utilizado no Brasil, nos cursos de microeconomia de pós-graduação ${ }^{12}$. A teoria do consumidor é toda ela exposta enfatizando-se a opinião de que seu valor é idêntico ao seu alegado conteúdo empírico. Todas as restrições impostas pela hipótese de agente maximizador seriam a obediência da restrição orçamentária e a existência de matriz de Slutsky simétrica e semidefinida. Depois da constatação de que a teoria gera as mesmas restrições que o axioma forte da preferência revelada, sendo, portanto, equivalente a este último, não encontramos no referido manual defesa de substituição da teoria antiga pela rival mais simples ou comentários sobre o

\footnotetext{
${ }^{10}$ FRIEDMAN, Milton. The Methodology of Positive Economics. In: FRIEDMAN, Milton. Essays on Positive Economics. Chicago: The University of Chicago Press, 1953. p. 3-43.
}

${ }^{11}$ McCLOSKEY, Donald. N. The Rhetoric of Economics. Journal of Economic Literature, Vol. 21, No. 2 (June 1983): 481-517.

${ }^{12}$ JEHLE, Geoffrey A. \& RENY, Philip J. Advanced Microeconomic Theory. Boston: Addison Wesley, 2001. projeto fracassado de abandono do conceito "meramente metafísico" de utilidade. Isso ocorre, entre outras razões, pela recusa tácita em abandonar os insights subjetivistas que a teoria original fornece e que embasam qualquer aula de graduação.

A inconsistência retórica se torna mais evidente quando, ao constatar que dados empíricos "infelizmente" se revelam incompatíveis com o axioma forte, os autores silenciam sobre a necessidade de abandono ou reformulação substancial da teoria, optando no lugar pela busca de critérios que digam quando tais violações não seriam importantes e pelo emprego de funções utilidade que minimizem essas violações ${ }^{13}$. Ao mesmo tempo que o conteúdo empírico da teoria favorecida se esvanece diante da complexidade do fenômeno econômico, na prática a exigência de conteúdo empírico é utilizada apenas para rejeitar retoricamente as teorias dos outros, que afinal não apresentam conteúdo empírico menor.

Embora o economista moderno não pratique as regras metodológicas que prega, forçado a ser em certo sentido um apriorista envergonhado, a adoção do empirismo exerce um papel empobrecedor, na medida em que a exigência de operacionalidade aparente restringe sobremodo o tipo de problema investigado pelo economista. Problemas mais gerais, mais fundamentais, são descartados como metafísicos, sujeitos apenas à análise normativa. A ciência com $C$ maiúsculo acaba restrita a problemas tratados por modelos formais cujas variáveis explanatórias obrigatoriamente devem estar disponíveis nos bancos de dados existentes. Assim, nada mais desinteressante do que um seminário acadêmico de um departamento típico de economia, restrito a esse tipo particular de história econômica ou economia aplicada.

Mais grave ainda, a adoção de modelos operacionais simplificados diminui no analista a percepção da complexidade do mundo real: a apreciação de auto-organização, presente

\footnotetext{
${ }^{13}$ Idem, Ibidem., p. 92.
} 
nos autores clássicos, deu lugar à visão de engenheiro do economista do século $X X$, com a sua pretensão de dirigir uma economia a partir do conhecimento de poucos indicadores agregados.

Tudo isso, como afirmamos, abre espaço para que os austríacos, em conjunto com os demais economistas não comprometidos com amarras metodológicas formalistas e empiricistas, apontem para os problemas realmente relevantes e para explicações teóricas adequadas décadas antes de seus rivais, pois não se acanham diante das consequências da ação humana, da passagem do tempo e da limitação do conhecimento ${ }^{14}$.

Se esses fatores forem mesmo relevantes para economia, tal como acreditamos, não é de surpreender que no longo prazo o progresso científico requeira incursões ousadas em território subjetivo, refratário a medição objetiva. E, com efeito, o exame da história da disciplina nos mostra esse progresso, na direção oposta à das recomendações metodológicas do período. Como resume F. A. Hayek em sua célebre observação: "Provavelmente não é exagero dizer que todo avanço importante na teoria econômica durante os últimos cem anos foi mais um passo na aplicação consistente do subjetivismo"15.

A incompatibilidade do positivismo com o objeto de estudo das ciências sociais explica como uma escola, tida como antiquada desde os anos trinta, teima em gerar contribuições pioneiras ao longo de toda sua trajetória. Desde a revolução marginalista, Carl Menger nos oferece um subjetivismo expandido, não limitado à postulação de uma escala de preferência, mas que enfatiza estratégias de ação e as expectativas dos agentes, subjetivismo esse que culmina na caracterização misesiana do problema central da economia. Desde seus primeiros escritos, Hayek busca explanações macroeconômicas firmemente microfunda-

\footnotetext{
${ }^{14}$ IORIO, Ubiratan Jorge. Ação, Tempo e Conhecimento: A Escola Austríaca de Economia. São Paulo: Instituto Ludwig von Mises Brasil, 2011.

${ }^{15}$ HAYEK, F. A. The Counter-Revolution of Science. Indianapolis: Liberty Press, 1979. p. 52.
}

mentadas na ação individual e que enfatizam questões relativas às mudanças no conhecimento dos agentes e, portanto, às expectativas. Desde o início da revolução keynesiana os austríacos criticam o nível exagerado de agregação e falta de compromisso com o individualismo metodológico mostrado pela macroeconomia, criticas essas retomadas pela teoria moderna. Mises e Hayek foram pioneiros na análise da ação coletiva, antecipando vários temas identificados modernamente com a escola da escolha pública. Os austríacos também foram pioneiros do moderno estudo da auto-organização de sistemas complexos, desde a teoria da evolução da moeda de Menger até o conceito de ordem espontânea de Hayek, passando pela análise da complexidade da estrutura do capital que Mises enfatiza em seu argumento do cálculo econômico socialista. As várias limitações do modelo de competição perfeita e o desenvolvimento de uma teoria de processo com ênfase na atividade empresarial afloraram durante o mesmo debate, que em retrospecto deu razão ao lado austríaco. Hayek é visto ainda como pioneiro da moderna economia da informação, embora seu argumento central seja pouco compreendido. Por fim, a análise austríaca das instituições antecedem os trabalhos neoinsitucionais de Douglass North sobre as causas fundamentais do crescimento econômico.

Este último caso é ilustrativo. Depois de décadas de análise centrada em modelos que relacionam variáveis macroeconômicas agregadas, ignorando a preocupação clássica, austríaca e neoinstitucional com a instituição da propriedade privada, a teoria do crescimento econômico finalmente reconhece tardiamente, no final do século passado, a centralidade das instituições ${ }^{16}$. No debate do cálculo econômico socialista, do mesmo modo, a importância da propriedade privada para o funcionamento dos mercados foi desdenhada como ideológica ou extra-econômica pelos

\footnotetext{
16 Ver, como ilustração: ACEMOGLU, Daron \& ROBINSON, James. Why Nations Fail: The Origins of Power, Prosperity, and Poverty. New York: Crown, 2012.
} 
participantes neoclássicos do debate ${ }^{17}$. Meio século depois, quando retomado o debate sob o ponto de vista da economia da informação, um comentador ${ }^{18}$ reconhece não apenas $\mathrm{o}$ papel da propriedade para solução efetiva de problemas de agente-principal, como recupera a noção clássica e austríaca de competição como processo que envolve rivalidade (em contraste com a teoria do equilíbrio em competição perfeita). Apesar disso, depois de utilizar argumentos austríacos do debate original, tal comentarista os classifica como 'palpites brilhantes', baseados na 'visão' de Ludwig von Mises e de F. A. Hayek e não como argumentos baseados em alternativa teórica legítima. $\mathrm{O}$ mesmo fenômeno ocorre na análise de Joseph Stiglitz do mesmo debate ${ }^{19}$.

Essa atitude, bastante comum, é representada pelo famoso comentário de Milton Friedman, para quem "não existe economia austríaca - apenas economia boa e economia ruim $^{\prime 20}$. Segundo o autor, as contribuições passadas austríacas poderiam ser incorporadas ao mainstream.

Essa avaliação, porém, não é consistente com a falta de apreço pelo estilo de pesquisa austríaco. Será mesmo interessante para o economista moderno adotar o modelo de expectativas adaptativas empregado por Friedman em suas teorias, apenas incorporando contribuições austríacas passadas e persistindo no erro sistemático de não levar a sério em cada instante do tempo as pesquisas austríacas? Ou será racional de vez em quando abandonar a adesão retórica ao dito de William Thomson (1824-1907), o Lord Kelvin, e examinar teorias que, embora

${ }^{17}$ Tome como exemplo: LERNER, Abba P. Theory and Practice in Socialist Economics. Review of Economic Studies, Vol. 6, No. 1 (October, 1938): 71-75.

18 KORNAI, János. Market Socialism Revisited. In: BARDHAN, Pranab K. \& ROEMER, John E. (Ed.). Market Socialism: The Current Debate. Oxford: Oxford University Press, 1993. p. 42-68.

${ }^{19}$ STIGLITZ, Joseph. Whither Socialism? Cambridge: The MIT Press, 1994.

${ }^{20}$ Citado em: DOLAN, Edwin G. Austrian Economics as Extraordinary Science. In: DOLAN, Edwin G. (Ed.). The Foundations of Modern Austrian Economics. Op. cit. p. 4. tenham o mesmo conteúdo empírico reduzido que qualquer outra teoria na esfera social, tratem de problemas fundamentais?

As teorias austríacas teriam maior impacto no desenvolvimento das ciências sociais se o caminho árduo, que procura sinceramente entender, com o propósito de aprender via diálogo crítico quais são os problemas estudados por uma tradição, não fosse preterido pela alternativa mais cômoda, a tradução de teorias rivais para o próprio referencial. Assim traduzidas, estas se tornam francamente errôneas ou, na melhor das hipóteses, triviais, bloqueando assim qualquer diálogo construtivo. Esse, infelizmente, é a atitude padrão das análises ortodoxas de trabalhos austríacos. Como resultado, a competição entre ideias dá lugar a ilhas protecionistas tomadas por paradigmas incomensuráveis entre si.

\section{II}

Se um maior diálogo crítico com a Escola Austríaca pode ser enriquecedor para o restante da comunidade acadêmica, como argumentamos acima, para os austríacos tal diálogo é fundamental. Afinal, o protecionismo empobrece de forma mais séria as comunidades pequenas. E o que poderia refletir a defesa do isolamento senão a tácita falta de confiança na capacidade do pensamento austríaco de competir no mercado das ideias ou a pretensão de que o conhecimento presente é quase completo? Nesta seção, argumentamos que a consolidação de uma comunidade acadêmica austríaca, ainda que relativamente pequena, traz consigo o risco de isolamento, o que seria fatal para o futuro da Escola Austríaca.

Antes de examinar esse risco, vejamos porque a comparação entre mercados e ciência não é mera metáfora. Como notou W. W. Bartley III (1934-1990), os argumentos em prol da liberdade formulados por Karl Popper e F. A. Hayek têm a mesma estrutura falibilista ${ }^{21}$,

${ }^{21}$ Ver: BARTLEY III, W. W. \& RADNITZKY, G. Evolutionary Epistemology, Rationality and the Sociology of Science. La Salle: Open Court, 1987. 
o que justifica que ambos sejam classificados como epistemologistas evolucionários: diante da capacidade cognitiva limitada (dos cientistas e dos agentes) em relação à complexidade dos problemas enfrentados (descoberta de teorias científicas mais próximas do mundo real e conjecturas empresariais mais compatíveis com os fundamentos da economia), o aprendizado ocorre mediante processo que envolve variação e seleção (na ciência: conjecturas e refutações; nos mercados: liberdade empresarial e operação do mecanismo seletivo de lucros e perdas) ${ }^{22}$.

Concretamente, isso significa que o progresso científico requer dois ingredientes: a liberdade para que as pessoas possam formular hipóteses diferentes e espírito aberto para o diálogo crítico. Da mesma forma que as teorias da competição não nos ensinam como competir nos mercados, a filosofia da ciência falibilista não requer que se estabeleça em cada controvérsia que hipóteses são definitivamente falsas, como sugere a leitura superficial de Popper ${ }^{23}$. Nas duas esferas, temos apenas uma teoria institucional sobre o progresso: este ocorre quando há crítica ou competição entre ideias e a estagnação impera quando o protecionismo intelectual predomina, resultando em dogmatismo.

Se por um lado a relevância e o grau de consistência interna entre as partes de uma estrutura teórica dependem da efetividade do discurso crítico, a diversidade inicial de ideias que circulam em uma comunidade científica depende não apenas da criatividade de seus membros, mas também da potencialidade inerente às ideias constituintes da tradição teórica: cada hipótese implica logicamente um conjunto infinito de proposições dela deduzidas, incluindo a negação de teorias rivais que

\footnotetext{
${ }^{22}$ A epistemologia evolucionista examina as diferenças e semelhanças entre diversos tipos de processos de aprendizado por tentativas e erros.

${ }^{23} \mathrm{O}$ caráter não justificacionista da filosofia popperiana é discutida em: BARTLEY III, W.W. Rationality versus the Theory of Rationality. In: BUNGE, Mario (Ed.). The Critical Approach to Science and Philosophy. London: Collier-Macmillan, 1964. p. 3-31.
}

possam futuramente surgir ${ }^{24}$. Isso implica que ideias também têm consequências não intencionais e que futuras conexões entre ideias originárias tanto na própria tradição teórica quanto emprestadas de suas rivais podem resultar na emergência de explicações surpreendentes, que podem inclusive desagradar ao autor de uma conjectura inicial.

Segundo essa concepção, a exploração efetiva dessa potencialidade requer o estímulo criativo dado pela exposição a explicações diversas e o estímulo providenciado pela crítica, ambos resultantes de um livre mercado de ideias. Se esse for o caso, diante da presente consolidação de uma comunidade de pesquisadores austríacos, o principal desafio para o futuro da Escola Austríaca será evitar que essa se feche em uma comunidade isolada, como no pesadelo elogiado por Thomas Kuhn ${ }^{25}$.

O desafio é recente. Ao contrário de várias escolas de economia, a Escola Austríaca se notabilizou desde sua origem pelo valor dado ao discurso crítico sério. Carl Menger era profundo conhecedor tanto dos autores clássicos britânicos quanto daqueles associados à escola histórica alemã. Além de polemizar com estes últimos no methodenstreit, mantinha correspondência ativa com os economistas das demais vertentes da então jovem economia neoclássica. Eugen von Böhm-Bawerk (18511914) apresenta e critica todas as teorias de capital e juros até então existentes, antes de oferecer sua própria explicação. Ludwig von Mises critica o socialismo com sólido conhecimento da doutrina marxista. A mesma erudição bohm-bawerkiana é mostrada por F. A. Hayek, que refez a história intelectual de todo problema que abordou, além de se envolver em controvérsias com os principais economistas de sua época. Ludwig Lachmann

${ }^{24}$ O caráter insondável do conhecimento científico é discutido em: BARTLEY III, W.W. Unfathomed Knowledge, Unmeasured Wealth - On Universities and the Wealth of Nations. La Salle: Open Court, 1990.

${ }_{25}$ KUHN, Thomas. A Estrutura das Revoluções Científicas. Trad. Beatriz Vianna Boeira e Nelson Boeira. São Paulo: Perspectiva, 2013. 
(1906-1990) desenvolve a teoria do capital austríaca sem descuidar da crítica ao neoricardianismo então emergente. A teoria da ação empresarial de Israel Kirzner deve parte de seu poder de convencimento ao conhecimento profundo por parte de seu autor da lógica da teoria microeconômica tradicional, que possibilitou a identificação das reais limitações desta última. Por outro lado, as contribuições de todos esses autores austríacos dependeram de forma fundamental do empréstimo de ideias pinçadas fora da tradição.

Mas, com o status recém adquirido de "escola de pensamento econômico", os austríacos incorrem no risco de negligenciar a aplicação de seu rico acervo de teorias aos problemas econômicos concretos e a atividade de crítica das explicações rivais em favor do foco excessivo em controvérsias metodológicas e de historiografia das próprias ideias, com o propósito de identificar a "verdadeira" doutrina austríaca, como se essa tradição não fosse marcada sempre pela enorme riqueza de influências filosóficas, políticas e econômicas diversas e com frequência conflitantes entre si.

A recomendação prática derivada dessa observação é a adoção de uma postura ativa, por parte do empresário intelectual austríaco, voltada para a busca de oportunidades até então não percebidas de desenvolvimento intelectual. Como na teoria do capital $^{26}$, o edifício do conhecimento científico presente, herdado como fóssil de planos passados, deve ser recombinado segundo os propósitos presentes do pesquisador. O investigador austríaco deve, de forma oportunista e eclética, estar atento aos trabalhos teóricos alheios, com o propósito de, em primeiro lugar, aproveitar boas ideias que possam ser combinadas com as doutrinas austríacas já existentes e, em segundo lugar, estar atento às deficiências dessas mesmas teorias, para emendá-las com insights austríacos, se isso for possível.

Esse é o espírito das recomendações de Peter Boettke para o desenvolvimento da Escola

${ }^{26}$ LACHMANN, Ludwig. Capital and its Structure. Kansas: Sheed and McMeel, 1978.
Austríaca $^{27}$. Para ele, os austríacos formam subconjunto de uma comunidade mais ampla de importantes economistas filiados àquilo que denomina economia mainline, comprometida com a explicação do funcionamento da ordem espontânea dos mercados e enfatizando a importância da liberdade para a prosperidade. Essa comunidade mais ampla inclui desde o iluminismo escocês até os autores da escola de escolha pública, além dos economistas neoinstitucionalistas e aqueles associados à universidade da Califórnia.

Considere a escola da escolha pública como exemplo. Sua análise de falhas de governo, baseada na hipótese de que políticos e burocratas também são auto-interessados, complementa de forma interessante a análise austríaca das mesmas falhas, baseada por sua vez na hipótese de que esses agentes não são omniscientes: a tendência presente na primeira abordagem de enxergar apenas má intenção por parte dos políticos deve ser balanceada pela ênfase austríaca nas consequências não intencionais da ação humana, enriquecendo desse modo a compreensão dos processos políticos. Os austríacos, pioneiros no estudo da lógica da ação coletiva ${ }^{28}$, deveriam por sua vez incorporar com mais frequência os insights de James M. Buchanan (1919-2013) e Gordon Tullock em suas análises.

Embora tenham sido pioneiros na análise da evolução institucional e como essa afeta o desempenho econômico das sociedades $^{29}$, os

27 BOETTKE, Peter. Living Economics: Yesterday, Today, and Tomorrow. Oakland: Independent Institute, 2012.

28 Ver: MISES, Ludwig von. Bureaucracy. Grove City: Libertarian Press, 1983 [1944]; HAYEK, F. A. O Caminho da Servidão. Trad. Anna Maria Capovilla, José Ítalo Stelle e Liane de Morais Ribeiro. São Paulo: Instituto Ludwig von Mises Brasil, 6ª Ed., 2010 [1944].

${ }^{29}$ HAYEK, F. A. Direito, Legislação e Liberdade: Uma Nova Formulação dos Princípios Liberais de Justiça e Economia Política. Apres. Henry Maksoud; Trad. Anna Maria Copovilla, José Ítalo Stelle, Manuel Paulo Ferreira e Maria Luiza X. de A. Borges. São Paulo: Visão, 1985.; LACHMANN, Ludwig. The Legacy of Max Weber. Grove City: The Glendessary Press, 1971. 
austríacos modernos recentemente ficaram para trás nesse campo, não aproveitando a oportunidade de diálogo dada pelo sucesso da obra de Douglass North. Como nota Peter Boettke, uma das tarefas mais urgentes para a Escola Austríaca é a aplicação de suas teorias ao exame das consequências de conjuntos específicos de arranjos institucionais ${ }^{30}$. Em especial, em minha opinião, os austríacos devem considerar mais de perto os dilemas inerentes ao processo de transição institucional para uma economia livre ${ }^{31}$.

Existem ainda inúmeros desenvolvimentos modernos que merecem atenção maior dos austríacos. Ainda que existam excelentes trabalhos sobre o assunto $^{32}$, os austríacos deveriam dedicar mais espaço à análise da moderna economia da informação, já que esta embasa os mais recentes argumentos em favor da intervenção do estado na economia. No plano da divulgação política das ideias científicas, a mencionada lacuna se fez sentir recentemente nas críticas ao "obamacare": nenhum dos comentários que observei na imprensa ou internet no Brasil foi capaz de identificar (e criticar sob o ponto de vista austríaco) o argumento baseado em assimetrias de informação que é utilizado na defesa de tal programa.

Como acontece em qualquer abordagem, a tendência ao isolamento diminui a capacidade de atrair para si os estudantes mais promissores, cheios de dúvidas não respondidas e disposição ao estudo, atraindo em seu lugar indivíduos que encontram conforto em certezas e slogans, geralmente motivados por ideologias políticas. Entre novatos, como ilustração, encontramos com frequência traba-

${ }^{30}$ BOETTKE, Peter. What is Wrong with Neoclassical Economics (And What is Still Wrong With Austrian Economics). In: FOLDVARY, Fred E. (Ed.). Beyond Neoclassical Economics: Heterodox Approaches to Economic Theory. London: Edward Elgar, 1996. p. 22-40.

${ }^{31}$ Um desses dilemas é discutido em: BARBIERI, Fabio. Chutando a Escada para a Liberdade. In: BARBIERI, Fabio. A Economia do Intervencionismo. Apres. Ubiratan Jorge Iorio. São Paulo: Instituto Ludwig von Mises Brasil, 2013. p. 141-45.

32 Por exemplo: THOMSEN, Esteban F. Prices and Knowledge. London: Routledge, 1992. lhos que defendem a teoria de processo de mercado e criticam as teorias de competição perfeita e monopólio, sem no entanto mostrar compreensão do conceito básico de eficiência alocativa que informa a análise ortodoxa. Também é comum encontrar a opinião de que economistas neoclássicos defenderiam versão cardinalista da teoria da utilidade, crença esta que não sobreviveria a um folhear casual de qualquer manual de microeconomia. Isso é muito grave: os austríacos vão abandonar seu passado e aderir à prática tão comum entre os economistas modernos de substituir a crítica séria por distorções fáceis de combater?

Ainda mais comum é a recusa em estudar a teoria dos jogos, tendo como justificativa a errônea opinião de Ludwig von Mises de que esta trataria apenas de jogos de soma zero ${ }^{33}$. Esta opinião, formulada antes do desenvolvimento moderno da teoria, foi baseada na leitura do livro pioneiro de John von Neumann (1903-1957) e Morgenstern (1902-1977) ${ }^{34}$. Mas não apenas a teoria dos jogos moderna não se restringe a jogos de soma zero, como também os austríacos teorizam sobre agentes com interesses opostos, como na "guerra de preços" de que fala Carl Menger em sua teoria de formação competitiva de preços. Com efeito, a teoria de preços de Carl Menger, Eugen von Böhm-Bawerk e Friedrich von Wieser (1851-1926) ${ }^{35}$ tem o mesmo espírito da moderna teoria de leilões. Assim, a dispensa superficial da teoria deveria ser trocada pelo seu estudo sério, seguido de uma crítica austríaca pertinente aos seus pressupostos de racionalidade e informação, seguida de análise de até que ponto jogos evolucionários lidam com essas limitações.

${ }^{33}$ MISES, Ludwig von. Ação Humana: Um Tratado de Economia. Trad. Donald Stewart Jr. São Paulo: Instituto Ludwig von Mises Brasil, 3ª Ed., 2010. p. 151.

${ }^{34}$ NEUMANN, John von \& MORGENSTERN, Oskar. Theory of Games and Economic Behavior. Princeton: Princeton University Press, 1944.

35 Teoria analisada por: ENDERS, Anthony M. Neoclassical Microeconomic Theory: The Founding Austrian Version. London: Routledge, 1997. 
O cômodo isolamento ilustrado acima, se não for evitado, impedirá tanto o estímulo ao desenvolvimento das ideias austríacas quanto a propagação destas para o restante da academia. Evita-se tal risco com a adoção de postura falibilista, humilde e investigativa.

\section{III}

Na primeira parte deste editorial, sugerimos um trade off na teoria econômica entre operacionalidade empírica e relevância, pois teorias sobre fenômenos sociais não podem ignorar duas características centrais e não mensuráveis desses fenômenos, enfatizadas pelos austríacos: subjetivismo e complexidade. A convivência dessas duas características em um mesmo sistema explanatório gera, no entanto, uma tensão que marca o desenvolvimento da Escola Austríaca desde o seu início. A discussão do futuro dessa escola requer que examinemos esse outro dilema, ao qual nos voltamos agora.

Os austríacos salientaram, em suas defesas da interação descentralizada via mercados, a complexidade inerente à tarefa de coordenação dos planos individuais. Em época marcada pela crença na engenharia social, foram pioneiros no estudo da auto-organização de sistemas complexos, com sua ênfase nas consequências não intencionais da ação humana e formação de ordens espontâneas. $\mathrm{O}$ subjetivismo, por outro lado, enfatiza que os atos de escolha têm aspecto criativo - não são determinados por eventos externos. Apontar para a complexidade dos fenômenos econômicos, por sua vez, implica enfatizar a existência de barreiras à vontade dos agentes. De fato, a ação humana supõe obstáculos, como notou Ludwig von Mises. Quanto mais intensivo for o uso na teoria econômica de hipóteses que enfatizam esses obstáculos, porém, menor parece ser o espaço para $\mathrm{o}$ aspecto subjetivo: no limite, a escolha se torna determinada, ilusória ${ }^{36}$.

36 SHACKLE, G. L. S. Epistemics and Economics: A Critique of Economic Doctrines. Cambridge: Cambridge University Press, 1973.
Assim, não é de se admirar a relutância por parte dos austríacos em adotar hipóteses simplificadoras para representar, por exemplo, as restrições físicas ao processo produtivo, como faz a teoria tradicional por meio das funções de produção. $\mathrm{O}$ economista moderno, como consequência, tende a acreditar que o processo de minimização de custos é relativamente automático e não algo que envolva contínua atividade empresarial, necessária para descobrir as maneiras mais baratas de produzir diante das constantes alterações nos fundamentos da economia. Embora um austríaco não incorra nesse tipo de erro, sua opção teórica implica em um custo: os primeiros economistas austríacos trabalham com oferta fixa, exógena, em sua teoria dos preços. No entanto, os austríacos também adotaram simplificações teóricas, como referências à lei de rendimentos decrescentes na teoria da imputação, a adoção de processos produtivos do tipo input contínuo - output pontual na teoria do capital ou a abstração do elemento temporal na teoria da escolha.

Isso nos leva ao seguinte problema: o avanço da teoria austríaca requererá a adoção de hipóteses simplificadoras com mais frequência? Ou os austríacos devem evitar o uso de hipóteses não gerais, isto é, não derivadas da lógica da ação humana? Esse problema é especialmente pertinente se a Escola Austríaca pretende avançar na direção de desenvolver a teoria pura de ordens espontâneas, teorias aplicadas sobre consequências de arranjos institucionais específicos ou ainda estudos de caso que apliquem suas teorias puras em exemplos históricos.

A resposta a essa indagação passa pelo exame de como os austríacos lidaram com o dilema no passado. Consideremos a teoria de processo de mercado. Esta parte da lógica da escolha individual, algo puramente subjetivo. Mas os planos individuais podem entrar em choque com a realidade exterior, seja diretamente, na forma de restrições físicas independentes da vontade ou indiretamente, mediante as consequências dos planos dos demais agentes. As hipóteses que informam os planos 
dos agentes podem se revelar incompatíveis com essas restrições. Em outros termos, o conhecimento dos agentes é falível e, portanto, o subjetivismo não basta: é necessário fazer menção aos elementos do mundo real que frustram nossos planos. Essa é a essência do artigo seminal de F. A. Hayek, que propõe a busca por uma teoria de aprendizado, que investigue quais são as condições para que o conhecimento falível dos agentes nos mercados se torne progressivamente compatível com o mundo externo e com os demais planos ${ }^{37}$.

Ocorre que, como o mundo é complexo, as restrições variam segundo as circunstâncias particulares de tempo e local. Como analistas, não sabemos em cada caso quais são os detalhes dessas restrições. Hayek é levado assim a salientar, no mesmo artigo, a distinção crucial entre o conhecimento genérico do teórico e o conhecimento particular do agente. Mas, ao representar de forma simplificada as restrições no plano teórico, não devemos transferir essa simplicidade para as restrições do mundo real, marcada pela diversidade das condições particulares.

Isso nos leva de volta ao nosso problema original, que denominaremos dilema lachmanniano: a representação formal daquilo que pode frustrar um plano de um agente pode reduzir a percepção do analista a respeito da complexidade do problema da coordenação dos diferentes planos. Se por um lado o subjetivismo radical desconsidera a maneira como o mundo externo afeta as escolhas, enfatizando apenas o aspecto criativo da ação, a representação excessivamente simplificada das restrições tende a tornar as decisões subjetivas automáticas e mecânicas. Nas duas alternativas, a complexidade do problema alocativo, que embasa a defesa austríaca da liberdade, desaparece. Embora o problema também ocorra nas representações teóricas verbais, o uso do formalismo

37 HAYEK, F. A. Economics and Knowledge. Economica, Vol. 4, No. 13 (February, 1937): 33-54. Ver, também: HAYEK, F. A. O Uso do Conhecimento na Sociedade. Trad. Philippe A. Gebara Tavares. MISES: Revista Interdisciplinar de Filosofia, Direito e Economia, Vol. I, No. 1, jan.-jun. 2013: 153-62. matemático tende, na expressão de Lachmann ${ }^{38}$, a "ricardianizar" a teoria ${ }^{39}$, ou seja, reduzir a apreciação dos elementos subjetivistas e adotar hipóteses excessivamente simplificadas.

O dilema se coloca, porém, apenas se as entidades teóricas forem interpretadas como variáveis que possam ser potencialmente operacionalizáveis em termos empíricos. Metodologicamente, o dilema se dissolve se os conceitos teóricos forem encarados como representações de apenas de algum aspecto típico do fenômeno estudado, ou, nos termos de Hayek, vistos apenas como padrões abstratos ${ }^{40}$. Nesse sentido o conhecimento do analista tem natureza essencialmente diferente do conhecimento particular do agente. A hipótese de uma curva de custo em forma de U, por exemplo, não deve ser interpretada como algo estável, estimável econometricamente pelo economista, mas apenas como a constatação teórica útil de que, dado um tamanho fixo qualquer de planta, seria caro produzir nela apenas uma unidade de um bem, devido ao elevado custo fixo médio e também seria caro produzir quantidades muito altas, dada a hipótese de retornos decrescentes do fator variável, de modo que existem incentivos para produzir quantidade intermediária. Isso não implica que se possa diferenciar a função custo médio, igualar tal derivada a zero e encontrar a escala ótima de produção. $\mathrm{Na}$ concepção hayekiana, ao contrário do conhecimento abstrato do analista, o conhecimento necessário para minimizar custos no mundo real é algo que deve ser redescoberto diariamente pelos agentes.

${ }^{38}$ LACHMANN, Ludwig. Macroeconomic Thinking and the Market Economy: An Essay on the Neglect of the Micro-foundations and Its Consequences. London: Institute of Economic Affairs, 1973.

${ }^{39}$ No modelo ricardiano de crescimento, a exigência de tratabilidade faz com que tanto os planos subjetivos quanto as complexidades microeconômicas desapareçam sob agregados macroeconômicos, o que contribuiu para a mentalidade de engenheiro que caracteriza o moderno economista intervencionista.

${ }^{40}$ HAYEK, F. A. The Theory of Complex Phenomena. In: HAYEK, F. A. Studies in Philosophy, Politics and Economics. Op. cit., p. 22-42. 
Isso nos mostra que, se ferramentas teóricas forem interpretadas com sofisticação metodológica, é possível falar de complexidade sem que se perca de vista o subjetivismo e preservar o subjetivismo sem que se renuncie ao desenvolvimento teórico. $\mathrm{O}$ desenvolvimento austríaco passa então pela conscientização desse dilema metodológico para que se desenvolva e critique teorias sem cair nos defeitos postos por nosso dilema.

A despeito das peculiaridades das crenças metodológicas de cada economista austríaco, esse modo de lidar com a complexidade do mundo social é comum na obra de vários deles. Em Carl Menger, a multiplicidade de causas operando simultaneamente dita que a teoria pura, que ele denomina orientação de pesquisa exata, seja abstrata no sentido mencionado: ignora a maioria das causas e traça teoremas válidos derivados de subconjunto específico de hipóteses ${ }^{41}$. Menger, porém, ainda trabalha com a hipótese milliana de Homo economicus. Ludwig von Mises, tendo em vista a substituição realizada pela segunda geração de austríacos da plutologia pela lógica da escolha, abandona a hipótese específica de Homo economicus pelo axioma geral da $\mathrm{ação}^{42}$. A distinção entre teoria pura apriorista e investigações históricas que adotam hipóteses concretas, porém, se assemelha à tipologia mengeriana. F. A. Hayek, do mesmo modo, classifica os fenômenos segundo seu grau de complexidade, nota que o conteúdo empírico de uma teoria diminui com o aumento dessa complexidade e afirma que as ciências sociais lidam apenas com previsões de padrão, nunca previsões que envolvam detalhes dependentes de hipóteses subsidiárias concretas ${ }^{43}$.

\footnotetext{
${ }^{41}$ MENGER, Carl. Investigations into the Method of the Social Sciences. Grove City: Libertarian Press, 1996 [1883].

42 Ver, por exemplo: MISES, Ludwig von. Epistemological Problems of Economics. Auburn: Ludwig von Mises Institute, 2003 [1933].

${ }^{43}$ HAYEK, F. A. The Theory of Complex Phenomena. In: HAYEK, F. A. Studies in Philosophy, Politics and Economics. Op. cit., p. 22-42.
}

Essa tradição metodológica, embora soe exótica a ouvidos modernos, nada mais é do que a metodologia dominante até o advento do positivismo na década de trinta do século passado. Os austríacos, embora rejeitem a teoria clássica do valor, são herdeiros dos clássicos no que se refere ao método. Estes enfatizaram a complexidade do fenômeno econômico e até mesmo o elemento subjetivo, a despeito de sua teoria objetiva do valor. Considere os principais tratados metodológicos da época. Nassau William Senior (17901864) fala de variáveis psicológicas (subjetivas) conhecidas por introspecção ${ }^{44}$. John Stuart Mill rejeita o formalismo matemático e o empiricismo precisamente por causa da maior complexidade do fenômeno econômico: existem muitas causas operando simultaneamente, não existem experimentos naturais para isolá-las, essas causas não são independentes entre si e seus valores se alteram continuamente ${ }^{45}$. John Elliott Cairnes (1823-1875), além disso, aponta para a impossibilidade de medição de causas 'psicológicas ${ }^{46}$.

Essa tradição ainda é dominante na primeira geração de economistas neoclássicos. O pai de John Maynard Keynes (18831946), John Neville Keynes (1852-1949), em seu influente tratado metodológico, defende a teoria abstrata e dedutiva frente ao ataque historicista ${ }^{47}$, aceitando em linhas gerais a postura de Carl Menger no methodenstreit. Embora os primeiros neoclássicos ainda não sejam empiricistas, defendem o formalismo matemático. Vários deles esposam exatamente a interpretação acima exposta dos conceitos teóricos, vistos como entidades abstratas utilizadas para ilustrar o princípio de funciona-

${ }^{44}$ SENIOR, Nassau William. An Outline of the Science of Political Economy. New York: Augustus M. Kelley, 1965 [1836].

${ }^{45}$ Ver quinta parte de: MILL, John Stuart. A System of Logic. Op. cit.

${ }^{46}$ CAIRNES, John Elliott. The Character and Logical Method of Political Economy. Kitchner: Batoche Books, 2001 [1888].

${ }^{47}$ KEYNES, John Neville. The Scope and Method of Political Economy. Kitchener: Batoche Books, 1999. [1890]. 
mento das estruturas sociais complexas e não como representações concretas de valores mensuráveis. Antoine Augustin Cournot (1801-1877), embora aceite que não é possível medir curvas de demanda, afirma que estas curvas, interpretadas abstratamente são imprescindíveis para o desenvolvimento da teoria de oligopólio ${ }^{48}$. Léon Walras (18341910) trata sua teoria como uma explicação de princípio de funcionamento dos mercados ${ }^{49}$. Francis Ysidro Edgeworth (1845-1926), por sua vez, defende em economia teórica o que chama de "matemática sem números"50. Essa tradição segue até John Maynard Keynes, que depois de elogiar a utilidade do diagrama de oferta e demanda, assevera que a estimativa econométrica de uma curva de demanda destrói a utilidade desta como ferramenta de análise, que depende de seu caráter puramente abstrato ${ }^{51}$.

Essas referências não têm interesse apenas histórico, podendo contribuir para nossa discussão do futuro da Escola Austríaca. Será possível utilizar modelos formais interpretados dessa maneira, como fazem, por exemplo, os teóricos da auto-organização de sistemas complexos $^{52}$, que retomam temas hayekianos?

A história da teoria econômica no século vinte recomenda ceticismo: na década de trinta a metodologia clássica-austríaca foi substituída pelo empirismo. Com isso, o dilema lachmanniano se fez sentir com toda

${ }^{48}$ COURNOT, Antoine Augustin. Researches into the Mathematical Principles of the Theory of Wealth. London: MacMillian, 1897 [1838].

49 WALKER, Donald. A. Walrasian Economics. Cambridge: Cambridge University Press, 2006.

50 EDGEWORTH, Francis Ysidro. Mathematical Psychics: An Essay on the Application of Mathematics to the Moral Sciences. London: C Kegan Paul, 1881.

51 KEYNES, John Maynard. Economic Model Construction and Econometrics. In: HAUSMAN, Daniel M. (Ed.). The Philosophy of Economics: An Anthology. Cambridge: Cambridge University Press, 1994.

${ }^{52}$ Para uma introdução a essa literatura, que merece especial atenção dos austríacos, ver: MILLER, John H. \& PAGE, Scott E. Complex Adaptive Systems: An Introduction to Computational Models of Social Life. Princeton: Princeton University Press, 2007. a força: o modelo de equilíbrio geral walrasiano, de representação abstrata da complexidade da coordenação via sistema de preços, transformou-se em ferramenta de planejamento central no debate do cálculo econômico socialista. A própria abordagem de sistemas complexos aplicada à economia peca pela ausência do elemento subjetivo e, quando usada por economistas, ainda se preocupa com otimalidade em vez de adaptação ${ }^{53}$.

A despeito disso, a tendência a ricardianizar a teoria talvez seja algo inerente ao espírito empirista da época e não característica inerente às teorias. Afinal, os biólogos são capazes de distinguir cuidadosamente entre modelo (como explicação de princípio) de seleção artificial e processo real de seleção natural ${ }^{54}$. Talvez isso ocorra porque nesse campo é possível literalmente observar ordens espontâneas se formando, o que torna evidente a emergência de soluções adaptativas não consideradas pelo modelo abstrato.

Seja qual for a resposta ou caminho tomado pelos pesquisadores austríacos no futuro, explorar possibilidades não é algo perigoso se formos instruídos por atitude falibilista, receptiva à crítica. Lembrando Karl Popper, deixemos as idéias morrem em nosso lugar!

Diante dos argumentos expostos neste editorial, gostaríamos de enfatizar o compromisso da MISES com a postura falibilista aqui defendida, expressa na busca sincera de diálogo com outras correntes de pensamento, nos diversos campos relevantes para o desenvolvimento do conhecimento sobre o funcionamento das sociedades. É com grande satisfação que, em nome de toda a equipe editorial, tenho a honra de apresentar ao leitor a presente edição deste periódico. Que a leitura deste volume estimule a descoberta de novas idéias, cuja discussão preencha as páginas das edições seguintes! cos

\footnotetext{
${ }^{53}$ Uma crítica austríaca a esses defeitos é esboçada em: BARBIERI, Fabio. Complexity and the Austrians. Filosofía de la Economía. Vol. 1, No. 1, 2013.
}

54 DAWKINS, Richard. A Escalada do Monte Improvável: Uma Defesa da Teoria da Evolução. Trad. Suzana Sturlini Couto. São Paulo: Cia. das Letras, 1998. 